\title{
Ilhas desertas, ilhas desconhecidas, literatura e medicina
}

\author{
Deserted islands, unknown islands, literature end \\ medicine
}

DAVINA MARQUES*

Resumo: Este artigo, ensaístico, aproveita-se de uma discussão inicial sobre ilhas desertas e ilhas desconhecidas, proposta pelo filósofo francês Gilles Deleuze, para propor pensar sobre a relação entre a literatura e a medicina. Entre exemplos literários e de pesquisa acadêmica, busca-se reafirmar as potências e possibilidades desse relativamente novo campo teórico das narrativas médicas, como se fosse um convite que instigasse a procura de algo novo, ainda por vir. Aponta para uma questão que ultrapassa a moral, a ética, para organizar-se esteticamente a fim de promover os movimentos para aquilo que ainda não há.

Palavras-chave: literatura, medicina, filosofia deleuziana

\begin{abstract}
This article, in an essayistic approach, begins with a discussion on deserted and unknown islands, by the French Philosopher Gilles Deleuze, in order to propose relations between literature and medicine. Among literary and academic research examples, we have highlighted the potencies and the possibilities of this relatively new theoretical field of narrative medicine, as if it were an invitation to the quest for something new, still to come. We have addressed an issue that goes beyond the moral guidelines and even ethics, in order to promote, aesthetically, the flows to the direction of what is not here yet.
\end{abstract}

Keywords: literature, medicine, deleuzian philosophy

* Doutora em Estudos Comparados de Literaturas de Língua Portuguesa (USP). Docente no Instituto Federal de Educação, Ciência e Tecnologia de São Paulo - Hortolândia (IFSP-HTO), Área Núcleo Comum - Ensino de Línguas: Português e Inglês. 
Dá-me um barco [...] E tu para que queres um barco [...].

Para ir à procura da ilha desconhecida, respondeu o homem,

Que ilha desconhecida, perguntou o rei disfarçando o riso, como se tivesse na sua frente um louco varrido [...], A ilha desconhecida, repetiu o homem, Disparate [...], Estão todas nos mapas, Nos mapas só estão as ilhas conhecidas [...] José Saramago

m "Causas e razões das ilhas desertas", um manuscrito que Gilles Deleuze nunca chegou a publicar, mais tarde apresentado ao público na coletânea $A$ ilha deserta (2006), o filósofo nos lembra que há dois tipos de ilhas: as continentais, acidentais ou derivadas, que foram separadas de um continente por uma desarticulação, uma erosão ou fratura; e as ilhas oceânicas, que são ilhas originárias, constituídas, por exemplo, de corais, de erupções submarinas. Para o autor, elas nos dão testemunhos da oposição entre o oceano e a terra: "Umas nos fazem lembrar que o mar está sobre a terra, aproveitando-se do menor decaimento das estruturas mais elevadas; as outras lembram-nos que a terra está ainda aí, sob o mar, e congrega suas forças para romper a superfície." (DELEUZE, 2006, p. 17). Essas ilhas podem ser ou estar desertas.

Pode nos parecer normal que haja ilhas desertas pelo mundo, mas, para o homem, continua o filósofo, isso se transforma em desafio: uma tentativa de pôr fim a essa oposição entre terra e mar, dominando esse combate vivo, assumindo controle da ilha. Deleuze afirma que aquilo que conduz o homem às ilhas, que o faz sonhar com as ilhas, tem a ver com o duplo movimento que as produz, continental ou oceânico, das fraturas ou das erupções. No entanto, o homem é aquele que recria o mundo a partir da ilha e sobre as águas: "Sonhar ilhas, com angústia ou alegria, pouco importa, é sonhar que se está separando, ou que já se está separado, longe dos continentes, que se está só ou perdido; ou, então, é sonhar que se parte de zero, que se recria, que se recomeça." (Ibidem, p. 18). O homem poderia, ao chegar a uma ilha, criar, mas os exemplos que Deleuze nos oferece, ao contrário, são de re-criação do que já se conhece. Ele afirma 
ainda que a literatura, como espaço ensaístico de interpretação daquilo que não conseguimos explicar e que mal conseguimos imaginar, também demonstra a falência da empreitada humana em relação às ilhas. Citando Robinson Crusoe e Suzanne et le Pacifique, o filósofo nos mostra um Robinson interessado em reproduzir a vida cotidiana burguesa, incapaz de propor algo novo, fazendo apenas com que tudo seja "aplicado" na ilha, inclusive as relações de poder estabelecidas com o "escravo" Sexta-feira; e observa em Suzanne que nada ali também é criado, pois a ilha lhe oferece um "duplo" de tudo o que já existia na cidade.

O movimento ensaístico da literatura, então, poderia ser aquele que nos convida à abertura para o que ainda não há. Um exemplo seria $O$ conto da ilha desconhecida, de José Saramago. Em busca da ilha cuja existência se ignora, o homem e a mulher, personagens, nos convidam a chamar a própria embarcação de ilha desconhecida, para lançar-se "enfim ao mar, à procura de si mesma" (SARAMAGO, 1998, p. 62). Poder-se-ia imaginar que o homem e a mulher estariam simplesmente retomando aquilo que sempre souberam fazer, aptos então apenas a re-criar as mesmas condições de vida em qualquer lugar onde, porventura, venham a colocar seus pés. Por outro lado, no encontro com uma ilha deserta, talvez tivessem uma oportunidade única: brincando com as palavras de Shakespeare, poder-se-ia dizer que há também mais coisas entre os mares e as terras do que podemos imaginar.

\section{Uma saúde que falta}

Gilles Deleuze, sabemos, interessou-se muito pela literatura, ainda que não tenha escrito livros teóricos para essa área, como os fez para o cinema, por exemplo. Trabalhar criativamente com conceitos filosóficos, para ele, sempre funcionou bem na relação com a arte: a pintura, o cinema, o texto literário. Nas palavras de Catarina Pombo Nabais (2008, n.p.), "o conjunto dos textos de Deleuze sobre a literatura parece ser [...] o arquivo vivo de conceitos, de categorias, de temas, de abordagens da literatura que desenharam a atmosfera teórica das últimas décadas". Se isso não pertence a uma teoria literária, o motivo é simples, continua a pesquisadora portuguesa: Deleuze quer aceder a outras coisas, que vão além da teoria literária, da compreensão da literatura, dos dispositivos narrativos. Ele quer pensar filosoficamente a vida a partir do que percebe na 
literatura. Daí o interesse de ver seus conceitos funcionando para pensarmos outros temas, outras áreas.

Interessa a Gilles Deleuze, com ou sem o parceiro Félix Guattari, na literatura, investigar a sua potência fabulatória, capaz de criar intensidades e forças que podem libertar o homem daquilo que o aprisiona, em direção a um outro povo, um povo que falta. ${ }^{1}$

Deleuze se aproximou de Friedrich Nietzsche ao afirmar que o artista é uma espécie de "médico cultural", capaz de diagnosticar uma "doença" social e, como um médico, propor uma "cura" em sua obra. ${ }^{2}$ Essa cura é a invenção de uma outra forma de vida.

Para Gilles Deleuze, na literatura, o escritor é um

[...] médico, médico de si próprio e do mundo. O mundo é o conjunto dos sintomas cuja doença se confunde com o homem. A literatura aparece, então, como um empreendimento de saúde [...]. A saúde, como literatura, como escrita, consiste em inventar um povo que falta. Compete à função fabuladora inventar um povo [...]. (DELEUZE, 1997, p. 13-4)

Essas são percepções determinantes para as duas áreas. O que muda quando entendemos tanto a medicina quanto a literatura como questões de saúde? Seria possivel pensarmos em uma "saúde que falta"?

Antes de tentar responder, faz-se necessário abordar, ainda que brevemente, a questão da não-saúde. Carlos E. Pompilio (2013, p. 13) discute essa "aflição humana" a partir das palavras em inglês disease, sickness e illness. Disease é o dessaranjo (anatômico, bioquímico, genético ou psicológico) que pode ser lido nos tratados de medicina; illness é aquilo que se apresenta quando se tem esse dessaranjo (disease), com sintomas e sinais que podem ser observados por um agente da saúde; e sickness (ou predicament) tem a ver com "as perspectivas sociais, psicológicas e/ou econômicas advindas do infortúnio da disease". Pompilio observa, então, que esse estado patológico parece nos afastar de uma vida saudável e feliz: como disease, deveria ser evitado; como illness, combatido; e como sickness, apagado e ocultado.

1 Sobre Deleuze e fabulação, Cf. Bogue, 2010; 2011, e Marques, 2013.

2 Cf. "A literatura e a vida", de Crítica e Clínica (DELEUZE, 1997). 
A não-saúde, um processo de adoecimento, continua Pompilio (2013), permite, por outro lado, a reconfiguração de nosso "estar-no-mundo", principalmente a partir do sentido que o enfermo venha a atribuir ao seu estado no movimento de uma saúde por vir.

As práticas de saúde, por sua vez, em seus meios e fins, ensina-nos José Ricardo C. M. Ayres (2004), deveriam então extrapolar a normalidade morfofuncional, a fim de atrelar-se a uma ideia de felicidade. Dessa forma, a saúde não seria definida como um estado completo de bem-estar ou normalidade, mas como uma experiência de valor positivo, em um horizonte sempre movente:

A idéia de felicidade busca [...] escapar tanto à restrição da conceituação de saúde a [um] horizonte tecnocientífico estrito quanto a uma ampliação excessivamente abstrata desse horizonte, tal como a clássica definição da saúde como "estado de completo bem-estar físico, mental e social" difundida pela Organização Mundial de Saúde no final dos anos 70 (Alma-Ata, 1978). Ao se conceber a saúde como um "estado" de coisas, e "completo", inviabiliza-se sua realização como horizonte normativo, já que este, como qualquer horizonte, deve mover-se continuamente, conforme nós próprios nos movemos, e não pode estar completo nunca, pois as normas associadas à saúde, ao se deslocarem os horizontes, precisarão ser reconstruídas constantemente. Já a noção de felicidade remete a uma experiência vivida valorada positivamente, experiência esta que, freqüentemente, independe de um estado de completo bem-estar ou de perfeita normalidade morfofuncional. É justamente essa referência à relação entre experiência vivida e valor, e entre os valores que orientam positivamente a vida com a concepção de saúde, que parece ser o mais essencialmente novo e potente nas recentes propostas de humanização. (AYRES, 2004, p. 19)

Entendermos a medicina e a literatura como questões de saúde tem a ver com essa reconfiguração de nosso lugar no mundo. $E$, se estabelecermos um paralelo com o "povo por vir", deleuziano, isso parece ficar mais claro: a "saúde", ou a "saúde que falta", nunca será um dado posto, algo que já esteja ali, pronto. É horizonte movente. Funcionaria como o conceito deleuziano de "povo por vir": é um povo que falta, um coletivo inexistente e criado como integrante de uma sociedade que ainda não se concretizou e que, no entanto, vibra, está lá. "A invenção de um povo por vir tem a ver [...] com a expressão de forças potenciais, 
com a capacidade de transformar essa força em positividade, e de multiplicá-la" (MARQUES, 2013, p. 43).

Uma saúde por vir, a saúde que falta, não é a ausência total de não-saúde. Seria, ao contrário, um exercício de entender cada vez melhor o homem, com suas limitações e suas grandezas. A saúde por vir, ainda inexistente, vibra, para além do bem e do mal, com Nietzsche:

[...] para além do bem e do mal pelo menos não significa para além do bom e do mau. Esse mau é a vida esgotada, degenerescente, [...] terrível, e capacitada a se propagar. Mas o bom é a vida emergente, ascendente, a que sabe se transformar, se metamorfosear de acordo com as forças que encontra, e que compõe com elas uma potência sempre maior, aumentando sempre a potência de viver, abrindo sempre novas "possibilidades". (DELEUZE, 2007, p. 172-3)

Uma saúde por vir, a saúde que falta, tem a ver com essa busca de novas possibilidades, a favor da vida.

\section{Empreendimentos de saúde}

Ana Maria H. Preve (2010; 2011) descreve invenções que têm como objetivo encontrar essas novas possibilidades de vida. Em pesquisa realizada com um grupo de pacientes internos de um hospital psiquiátrico, a autora se vê diante de pessoas que resistem, combatem, vivem, cada uma a seu jeito. A pesquisadora lembra o caso de Estamira, do filme homônimo, que vive do lixo de um aterro sanitário. Em sua perturbação, no encontro com o lixo, ela melhorou, afirma sua filha. Conta de Fabinho, ex-presidiário/a, ele-ela, soropositivo/a, certo/a de que ia morrer. Chorava ininterruptamente. Um dia chega uma carta, que faz dele/a a pessoa mais feliz do mundo. Preve apresenta-nos o andarilho, das vidas pelos espaços abertos e sem portas: agora tomado pelos medicamentos que o impedem de andar, escrever. Ele vai sair do hospital-prisão, mas está triste. Para sair precisa fazer uso de um medicamento que Ihe tira toda liberdade. Descreve também o artista que transforma as cartelas de medicamento, entintadas, em carimbos, em coleções de múltiplas formas e cores. E conta ainda de Águia, cujos dedos seguravam os lápis coloridos em lindas criações de mandalas. Essas cinco 
"invenções" retratadas em breves narrativas no seu texto de 2011 terminam sempre com uma pergunta: "Lixo, cura?", "Uma carta, uma cura?", "O tratamento, uma cura?", "Uma obra, uma cura?", "Mandalas, uma cura?" Seus escritos me fazem perguntar, afinal: literatura cura?

Muitas pesquisas têm nos mostrado que a aproximação entre literatura e medicina tem a maior importância na atualidade:

A relação entre texto e medicina parece absolutamente pertinente e ainda bem pouco explorada no meio acadêmico brasileiro. Críticos literários e linguistas analisam a relação entre: linguagem verbal e outras artes, linguagem verbal e novas tecnologias, linguagem verbal e linguagem verbal. Se a prática médica deve se basear na linguagem, onde estão os estudos relacionando justamente esses dois campos, o médico e o linguístico? (CARELLI; POMPILIO, 2013, p. 678)

Por exemplo, quando se estuda com detalhe, em análise comparatista, a maneira como o menino Miguilim se relacionava com doenças, como as descrevia e como os adultos o tratavam, pareceu-nos interessante observar os diversos modelos que atravessavam "Campo Geral”, do autor também médico João Guimarães Rosa, e Mutum, de Sandra Kogut (Cf. MARQUES; CARELLI, 2015). Há, no texto, alguns modelos, algumas formas de curar (além da ausência delas, que leva à morte): a do curandeiro, dos remédios amargosos e dos fortificantes, que não resolve por se preocupar mais com a doença do que com a causa; a do médico de longe, que leva a criança para "uma vida melhor", retirando-a do seio familiar e afetando-a de forma imprevisível para o resto da vida; e a do curador que vê, observa, escuta e devolve a alegria de viver, entre danças e cantigas, inspirando Miguilim a também contar suas histórias com um simples: "Te segura e pula, Miguilim, levanta já!", "apruma mesmo durim, [...] a dança hoje é das valsas." (ROSA, 1984, p. 64-65). O filme deixa de lado este último "modelo" ou forma de curar. Afinal, uma canção, uma dança, curam? Narrativas curam? Ou se trata de um cuidado especial daquele que ouve a nossa história?

Para Pompilio (2013), as narrativas são de suma importância. O enfermo é um narrador por excelência, cujas experiências, narradas, não podem ser apenas um material para coleta de dados. Um profissional de saúde, com ouvido atento, já está promovendo o cuidado. 
O estudo de Tatiana Piccardi (2015), "Transformando sofrimento em narrativa e narrativa em uma nova vida", indica a importância da empatia de um interlocutor para resultar em "efeitos curativos". Piccardi trabalhou com as falas das mães/pais pertencentes a um grupo de apoio a pais enlutados e com sua experiência como ghost writer de Andrei-Susan (que resolveu escrever sobre sua decisão de realizar a cirurgia de redesignação de gênero, a fim de transformar sua dor em narrativa).

Ainda que os "efeitos curativos" e o empoderamento identitário não possam ser explicados apenas pela narrativização das histórias pessoais, Piccardi entende ser necessário destacar as forças promotoras das narrativas:

Nos dois casos, observa-se a importância do interlocutor empático e do contexto promotor de suas falas. Embora os autores das narrativas sejam eles mesmos responsáveis pela afirmação e agenciamento da própria dor, é da interlocução que vem a resposta necessária que sustenta a afirmação e concretiza a agência. Entenda-se agência como um certo agir humano necessário à própria sanidade e/ ou manutenção do equilíbrio e que não se dá fora da relação com os demais. [...] Trata-se de ressignificar uma realidade, ou agenciar a construção de uma nova realidade a partir da dor que, em discurso, deixa de ser causa de uma ação para se tornar a ação em si mesma. $O$ sujeito que enuncia parece mover-se impulsionado por um instinto de sobrevivência que tem expressão linguística, e nasce e se alimenta de linguagem, entendida como interlocução entre pessoas ancoradas num tempo e lugar. Desta forma, [...] o enunciar/narrar com efeitos curativos pressupõe a existência de ao menos um interlocutor que estimule e seja receptivo à fala. Havendo interlocução empática, a narrativa curativa consolida-se como ato de fala curativo feliz, de acordo com terminologia de Austin, na medida em que estrutura uma dada vivência por meio da aceitação e compreensão de um passado, ao mesmo tempo em que, projetada no futuro, antecipa e constrói um futuro.[...] Tanto as narrativas dos pais enlutados, como a narrativa de Andrei-Susan, podem ser entendidas como narrativas motivadas pela dor que materializam, sob a forma de textos (orais ou escritos), uma ação curativa sobre o sujeito que narra/enuncia. O efeito curativo é constitutivo deste tipo de narrativa, sendo capaz de deslocar o sujeito das margens para o centro de sua própria história. (PICCARDI, 2015, p. 10) 
A narrativa, vemos também nesse exemplo, vai além de transmitir informações e transforma o narrador em construtor de sua própria história (cf. PLAPLER, 2015).

Criar contextos promotores da fala, levar o médico à empatia, são partes importantes da formação em medicina, pois a tendência é haver grande assimetria na relação médico-paciente. Fabiana B. Carelli e Carlos E. Pompilio (2013, p. 679), por exemplo, discutiram as relações de poder que entrecruzam essas duas posições de interlocução: "Quando um paciente está diante de um médico, expondo sua história, ele, paciente, é o 'iletrado'." O paciente narra, nos lembram os autores, mas é o outro quem atribui sentido a essa narrativa e escreve sua história.

Podemos citar Guimarães Rosa novamente. No conto "Famigerado", o doutor narrador mostra a sua capacidade ao manipular o valentão que o procura para saber o significado da palavra que dá título ao conto. $O$ jagunço mal sabe pronunciá-la. Vemos a sagacidade do homem culto diante do homem sem os mesmos recursos, este totalmente à mercê do primeiro.

"Famigerado" não descreve uma consulta médica, mas vemos o processo dialógico mental do doutor, que responde mentalmente às falas do jagunço, enquanto se prepara para dar a resposta final àquele que busca uma informação. Não é assim que funciona o médico em uma consulta? Percebe-se, no conto, uma anamnese em curso: "Perguntei: respondeu-me que não estava doente, nem vindo à receita ou consulta. [...] Muito de macio, mentalmente, comecei a me organizar." (ROSA, 1988, p. 57). Mesmo fora de uma consulta, o doutor se organiza, de macio. Sua posição é privilegiada.

O médico sabe que precisa estar atento. Enquanto o outro gagueja, atrapalha-se na fragilidade de "não saber", o detentor da cultura e do conhecimento vai se organizando, prepara-se para a ação. Vejamos alguns outros momentos desse processo:

Tomei-me nos nervos. O cavaleiro esse - o oh-homem-oh - com cara de nenhum amigo. Sei o que é influência de fisionomia. Saíra e viera, aquele homem, para morrer em guerra. Saudou-me seco, curto pesadamente. [...] E concebi grande dúvida. [...]

Aquele homem, para proceder da forma, só podia ser um brabo sertanejo, jagunço até na escuma do bofe. Senti que não me ficava útil dar cara amena, mostras de 
temeroso. Eu não tinha arma ao alcance. Tivesse, também, não adiantava. Com um pingo no i, ele me dissolvia. O medo é a extrema ignorância em momento muito agudo. O medo O. O medo me miava. [...]

- "Eu vim preguntar a vosmecê uma opinião sua explicada..." [...]

- "Vosmecê é que não me conhece. Damázio, dos Siqueiras... Estou vindo da Serra..." [...]

Damázio, quem dele não ouvira? O feroz de estórias de léguas, com dezenas de carregadas mortes, homem perigosíssimo. Constando também, se verdade, que de para uns anos ele se serenara - evitava o de evitar. Fie-se, porém, quem, em tais tréguas de pantera? Ali, antenasal, de mim a palmo! [...] A conversa era para teias de aranha. Eu tinha de entender-lhe as mínimas entonações, seguir seus propósitos e silêncios. (Ibidem, p. 56-9)

Diante de um paciente qualquer, um médico também reconhece a necessidade de seguir-lhe as intenções, entonações e silêncios, os mínimos indícios. Além da questão da atenção, há um planejamento estratégico da ação. Quando vamos a uma consulta, obviamente queremos uma solução para algum problema. Aquele que ouve nossas queixas de saúde precisa ter sentidos apurados para a busca de sintomas. O profissional de saúde precisa ter uma capacidade de realizar ainda por ser ensinada, constituindo um outro ver/olhar/sentir (cf. PAUL, 2014). ${ }^{3}$

Isso quer dizer que, ao ser treinado para ouvir, ver e examinar os sinais e sintomas, o médico estaria mais equipado para cuidar:

[...] é preciso não apenas estudar de que maneira os modelos narrativos orais e os escritos (bastante diferentes entre si) operam nas histórias contadas por médicos e por pacientes, mas, também, as diferentes auras de poder que circundam e/ou não circundam oralidade e escrita. No limite, o perigo de não perceber esses fenômenos está na constituição de uma fala poderosa e ininterrupta que cala definitivamente aqueles que se acreditam (ou são creditados como) incapazes dela. Nesse caso, não ouvir o doente na especificidade de suas narrativas pode, sim, levar à morte

3 Sheila A. Paul (2014) apresenta essa capacidade de realizar a partir de "critical thinking skills" (competências do pensamento crítico), a saber: análise, interpretação, autorregulação, inferência, explicação e avaliação. 
- "desenlace" que, como menciona Foucault na epígrafe ${ }^{4}$ deste texto, cerra para sempre a boca de quem conta. Um silêncio próprio dos "inocentes". (CARELLI; POMPILIO, 2013, p. 679)

\section{Atravessamentos morais, éticos ou estéticos?}

Existe um papel ético e político na medicina, que a narrativa e a literatura podem ajudar a revelar e, talvez, até construir. O médico americano Arthur Kleinman (2013) escreveu um artigo interessante destacando o aspecto moral do cuidado, quando sua esposa foi diagnosticada com Alzheimer e ele passou a ocupar o lugar de acompanhante de paciente em vez do lugar da sua profissão. Em "From Illness as Culture to Caregiving as Moral Experience", ele afirma que a experiência foi transformadora tanto do ponto de vista pessoal quanto profissional. Afinal, a experiência e a ansiedade da doença, experimentadas pelo paciente e pela família, e a busca pelo diagnóstico e pela cura, enfrentada pelo médico, são coisas bastante distintas, em sua opinião.

Kleinman lembra que já se preocupava há tempos com a relação médico-paciente/família, e que já se frustrara antes com suas tentativas de propagar o que chamou de um cuidado mais "humanizado". ${ }^{5}$ Não se trata apenas de "falar"

4 A epígrafe citada no texto é a seguinte: "[...] a narrativa árabe - eu penso em As mil e uma noites - também tinha, como motivação, tema e pretexto, não morrer: falava-se, narrava-se até o amanhecer para afastar a morte, para adiar o prazo desse desenlace que deveria fechar a boca do narrador. A narrativa de Shehrazade é o avesso encarniçado do assassínio, é o esforço de todas as noites para conseguir manter a morte fora do ciclo da existência" (FOUCAULT, 2009, p. 268).

5 Utilizo o termo "humanizado" entre aspas aqui e mais adiante porque foi o termo empregado pelos autores e porque não cabe aqui aprofundar sua definição. Em discussão recente com Gabriela S. Spagnol, essa pesquisadora questionou os diversos sentidos que "humanizado" pode carregar e, por isso, prefere apresentar o cuidado como "centrado no paciente" ou "centrado no que realmente importa para o paciente". O conceito de cuidado, continua, sofreu mudanças ao ser padronizado e transformado em protocolos, listas e procedimentos; perdeu a subjetividade e a empatia que deveriam permear seu exercício. Para Spagnol, o grande problema da área da saúde é que lhe falta um norte. As ações são planejadas tendo como interesse diagnosticar, tratar o paciente, atender o maior número de pessoas, salvar vidas, oferecer os mais avançados exames, a tecnologia de ponta - ações cujo foco é o processo, os profissionais e até a gestão de hospitais e empresas. Ensinar, aprender e aplicar a empatia não bastam para essa pesquisadora, a menos que a lógica da saúde seja também redesenhada. (cf. SPAGNOL; VALLER; AVELAR, 2015). 
mais durante a consulta ou de promover a narrativa como experiência em si. 0 processo do cuidado, de dar e receber cuidado, de lidar com as pequenas coisas do dia a dia, era isso que importava para a família. Não era isso, no entanto, o que preocupava os médicos. A ética dessa relação era uma mistura confusa de sentimentos e valores. Havia entre pacientes e cuidadores uma troca recíproca atravessada por momentos de afirmação, aceitação, emoção, presença (KLEINMAN, 2013).

O autor aponta, então, para a questão nevrálgica da relação, que, para ele, é de fundo moral e emocional. No aspecto clínico, continua Kleinman, o cuidado mexe tanto com a vida do médico quanto do paciente, pois tem a ver com fazer o bem para o outro, por mais óbvio que possa parecer essa afirmação. Para ele, trata-se de entender a questão moral na luta diária dos profissionais de saúde querendo ser úteis, compassivos, atentos e responsáveis, enquanto têm que lidar com a indiferença das regras, das contabilidades, dos custos e das exigências de tempo.

No entanto, se concordarmos com as premissas de Kleinman a respeito da estrutura e das demandas das escolas de medicina e dos hospitais, considerando-os, de certa forma, obstáculos ao cuidado; se o ensino e a aprendizagem sobre as experiências com a doença continuarem válidos; se cuidar tiver mesmo a ver com fazer o bem para o outro e para o mundo; se o cuidado é essencial para a prática da medicina, então podemos ampliar essa questão para além do âmbito emocional e moral, a fim de levá-la para além da conduta, para além dos princípios e regras que governam um indivíduo ou grupo. Moral parece relacionar-se a obrigações; enquanto que a ética é da ordem das valorações, de uma filosofia norteadora de ações e modos de vida (cf. DELEUZE, 1992).

José Ricardo C. M. Ayres, que também tem se dedicado a pensar sobre a necessidade de uma maior compreensão das relações entre os profissionais de saúde e pacientes, destaca a dimensão dialógica desse encontro: "[...] a abertura a um autêntico interesse em ouvir o outro" (AYRES, 2004, p. 23). Só vai haver cuidado, quando o profissional de saúde, não se conformando a um papel de porta-voz do conhecimento, tornar-se capaz de ouvir e fazer-se ouvir, afirma. Esse movimento, continua, está relacionado a um dispositivo importante nas propostas de "humanização da saúde": o acolhimento. Ayres entende esse movimento como ético, pois resulta na reconstrução de identidades: assume-se 
um compromisso, responsabiliza-se por questões do outro, e isso transforma as relações e as pessoas envolvidas. ${ }^{6}$

Poderíamos avançar para além da ética, ao aproximarmos a medicina da literatura, e explorar uma dimensão estética dessa relação. Parece claro ser preciso que haja, nessa prática, uma "fusão de horizontes", no sentido gadameriano, entre aqueles que cuidam e os que buscam cuidado. Esse conceito funciona para entendermos as práticas médicas, as práticas do cuidado, como aproximações. Hans-Georg Gadamer (1997) escreveu sobre a "fusão de horizontes" quando apontava para um deslocamento necessário para o ato da compreensão, da interpretação de textos. Esse deslocar-se

[...] não é nem empatia de uma individualidade na outra, nem submissão do outro sob os próprios padrões, mas significa sempre uma ascensão a uma universalidade superior, que rebaixa tanto a particularidade própria como a do outro. $\mathrm{O}$ conceito de horizonte se torna aqui interessante, porque expressa essa visão superior mais ampla, que aquele que compreende deve ter. Ganhar um horizonte quer dizer sempre aprender a ver mais além do próximo e do muito próximo, não para apartá-lo da vista, senão que precisamente para vê-lo melhor, integrando-o em um todo maior [...]. (GADAMER, 1997, p. 456)

Esse deslocamento Arthur Kleinman (2013) nos apresentou como uma arte: uma arte de viver, uma arte da prática médica, que eu gostaria de apontar neste trecho final do artigo de maneira diferente: como uma estética. Deixando de lado a concepção da estética como uma disciplina ou como reflexão teórica, exploro uma definição da estética aliada da criação, com o filósofo Daniel Lins (2012a; 2012b), inspirado em Nietzsche e Deleuze, uma est-ética. Ele alude ao que Etienne Souriau chamou de sentido implícito, em que a estética é definida como uma concepção da arte numa pessoa, numa época e numa plêiade de culturas. Essa estética é o que movimenta a criação, afirma Lins (no prelo): "Em toda a invenção há sempre a força criativa de uma [...] estética".

6 Essa ética, segundo Ayres (2004), precisa ainda atingir um plano político, que deixarei de fora neste artigo. Para ele, os profissionais de saúde, os gestores ou formuladores de ações públicas, eticamente envolvidos, assumem, dessa maneira, compromissos ampliados com a saúde, atingindo, então, o universo social e coletivo. 
Quando desenvolvemos nossas pesquisas no entre de duas grandes áreas do conhecimento, a literatura e a medicina, inclusive explorando noções da filosofia e das ciências, estamos funcionando no âmbito da criação, principalmente na criação de outras formas de vida.

Gilles Deleuze (1992), discutindo a obra de Michel Foucault, aponta o caminho que recusa a questão moral e destaca um posicionamento ético com valor estético. É essa estética, a estética da existência, que trago para esta reflexão final, como um convite que nos instigue à procura de algo novo, ainda por vir, no campo de estudos das narrativas médicas. Sabemos que

[...] a constituição dos modos de existência ou dos estilos de vida [...] é o que Foucault chama de ética, por oposição à moral. A diferença é esta: a moral se apresenta como um conjunto de regras coercitivas de um tipo especial, que consiste em julgar ações e intenções referindo-as a valores transcendentes (é certo, é errado...); a ética é um conjunto de regras facultativas que avaliam o que fazemos, o que dizemos, em função do modo de existência que isso implica. Dizemos isto, fazemos aquilo: que modo de existência isso implica? [...] [S]e há nisso toda uma ética, há também uma estética. $O$ estilo, num grande escritor, é sempre um estilo de vida, de nenhum modo algo pessoal, mas a invenção de uma possibilidade de vida, de um modo de existência. (DELEUZE, 1992, p. 125)

O exercício do pensamento é algo perigoso, afirma o filósofo; é o desejo de descobrir como "[...] nos tornamos outra coisa" (Ibidem, p. 19). Em Foucault, afirma Deleuze no mesmo trecho, pensar é, primeiramente, arquivo: uma questão de ver e falar, desde que o olho não fique nas coisas e chegue às "visibilidades" e desde que a linguagem ultrapasse as frases para alcançar os enunciados. Em segundo lugar, pensar é estratégia: situa-se no âmbito do poder, busca compreender como se constituem as ações sobre as ações, que nos incitam, induzem, desviam, facilitam ou dificultam, ampliam ou limitam, tornam mais ou menos provável um ato. E, por fim, Deleuze observa em Foucault um pensar arte, um pensamento-artista, atrelado aos processos de subjetivação e à constituição de novos modos de existência, novas formas de vida: a existência como obra de arte.

Nos estudos sobre literatura e medicina, entender a vida como obra de arte nos ajuda a buscar em outro lugar aquilo que ainda não vimos, aquilo que ainda 
não foi dito. Por isso, funciona tentar responder com Deleuze sobre o que somos capazes de dizer e ver hoje:

[...] que haja distinção entre ver e dizer, que os dois estejam separados por um afastamento, uma distância irredutível, significa apenas isso: não se resolverá o problema do conhecimento (ou melhor, do "saber") invocando uma correspondência, uma conformidade. Será preciso buscar em outro lugar a razão que os entrecruza e os tece um no outro. É como se o arquivo fosse atravessado por uma grande falha, que põe, de um lado, a forma do visível, de outro, a forma do enunciável, ambas irredutíveis. E é o fora das formas, numa outra dimensão, que passa o fio que as costura uma à outra e ocupa o entre-dois. (DELEUZE, 1992, p. 121)

Retomando a discussão inicial sobre as ilhas continentais e as oceânicas, as conexões possíveis entre a medicina e a literatura não têm a ver com acabar com a oposição terra e mar. Interessa-nos explorar os meios, os múltiplos caminhos, aproximar e distanciar, para ver melhor e com outros olhos, fazer de outras formas, aceder ao que ainda não está posto. Interessa-nos essa invenção existente em ambas, na literatura e na medicina, principalmente quando se engajam no encontro, na criação de uma outra forma de vida, na abertura para aquilo que ainda não há. Interessam-nos os fios da moral e da ética, mas também a questão estética, presentes nas duas. Ao navegarmos em direção de ilhas desertas ou ao pisarmos esses espaços ainda por construir, em nossas pesquisas, seguimos desejosos de ir além da mera aplicação, como a crítica apresentada por Gilles Deleuze à ação de Robinson Crusoe e de Suzanne.

Entender a ação dos profissionais de saúde esteticamente, autores dos seus próprios estilos, transitando pelos conflitos éticos que os atravessam cotidianamente, é um desafio, principalmente se estivermos nos apoiando teoricamente na filosofia deleuziana. A literatura é da ordem da vida e da matéria vivida sim, mas localiza-se no inacabado, no informe, nos desvios, nas experimentações, na criação de uma outra língua, uma nova sintaxe, para Deleuze: "Escrever é também tornar-se outra coisa que não escritor" (DELEUZE, 1997, p. 16). Assim o artista se faz "médico cultural", ele afirma, de si e do mundo, e isso leva a uma reconfiguração de nosso "ser e estar no mundo". Parafraseando, em torção de 
inspiração deleuziana, o profissional de saúde poderia ser considerado um artista.

Com uma nova sintaxe, com processos outros de criação, um médico pode se fazer artista, realizando o que um médico não artista talvez não consiga. Profissionais da saúde artistas engajam-se em uma saúde que falta, aproximam-se de um povo que falta, lidam com horizontes moventes, buscam a fusão de horizontes. No mapa atual da formação só estão as ilhas conhecidas, lembramos, com José Saramago. Assim, aproximando-se e apropriando-se de ilhas desertas e desconhecidas com uma estética da existência própria, entre literatura e medicina, poderemos concordar com a citação de Jean-Marie Gustave Le Clézio, apresentada por Deleuze (1997, p. 14) em "A literatura e a vida": "um dia talvez saberão que não havia arte, mas apenas medicina". Isso se não descobrirmos que, de tão imbricadas uma na outra, não havia medicina, havia apenas arte...

\section{Referências}

BOGUE, Ronald. Deleuzian Fabulation and the Scars on History. Edinburg: Edinburgh University Press, 2010.

Por uma teoria deleuziana de fabulação. Trad. Davina Marques. In: AMORIM, Antonio Carlos; MARQUES, Davina; DIAS, Susana Oliveira. Conexões: Deleuze e Vida e Fabulação e... Petrópolis, RJ: De Petrus; Brasília, DF: CNPq; Campinas, SP: ALB, 2011. p. 17-35.

CARELLI, Fabiana B.; POMPILIO, Carlos E. O silêncio dos inocentes: por um estudo narrativo da prática médica. Interface: Comunicação, Saúde, Educação, v. 17, n. 46, p. 677-681, jul./set. 2013.

DELEUZE, Gilles. Cinema 2 - A imagem-tempo. Trad. Heloísa de Araújo Ribeiro. São Paulo: Brasiliense, 2007. . Crítica e Clínica. Trad. Peter Pál Pelbart. São Paulo: Ed. 34, 1997. . A ilha deserta e outros textos. Textos e entrevistas (1953-1974). Organização de David Lapoujade. Trad. Luiz B. L. Orlandi. São Paulo: Iluminuras, 2006. A vida como obra de arte. In . Conversações. Trad. Peter Pál Pelbart. São Paulo: Ed. 34, 1992. p.118-126.

ESTAMIRA. Direção: Marcos Prado. Produção: Marcos Prado e José Padilha. Rio de Janeiro: RioFilme, 2005. 1 DVD (120m). 
FOUCAULT, Michel. Estética: literatura e pintura, música e cinema. In Ditos e Escritos, vol. III. Trad. Inês Autran Dourado Barbosa. 2. ed. Rio de Janeiro: Forense Universitária, 2009.

. A Hermenêutica do sujeito. Trad. Márcio Alves da Fonseca e Salma Tannus Muchail. São Paulo: Martins Fontes, 2004.

. História da sexualidade 3: o cuidado de si. Trad. Maria Thereza da Costa Albuquerque; Revisão técnica de José Augusto Guilhon Albuquerque. Rio de Janeiro: Edições Graal, 2005.

GADAMER, Hans-Georg. Verdade e método. Traços fundamentais de uma hermenêutica filosófica. Trad. Flávio Paulo Meurer. Petrópolis: Vozes, 1997.

KLEINMAN, Arthur. From Illness as Culture to Caregiving as Moral Experience. The New England Journal of Medicine, 368, p. 1376-1377, April 11, 2013.

LINS, Daniel. Estética como acontecimento - o corpo sem órgãos. São Paulo: Lumme, $2012 a$.

. Estética como acontecimento. In DIAS, Susana Oliveira, MARQUES, Davina; AMORIM, Antonio Carlos. Conexões: Deleuze e Arte e Ciência e Acontecimento e... Petrópolis, RJ: De Petrus; Brasília, DF: CNPq/MCT; Campinas, SP: ALB, 2012b. p. 17-36. . A Pele de Anna. (sobre a arte de Anna Maiolino). No prelo.

MARQUES, Davina. Entre literatura, cinema e filosofia: Miguilim nas telas. 2013. 227 p. Tese (Doutorado em Estudos Comparados de Literaturas de Língua Portuguesa) Faculdade de Filosofia, Letras e Ciências Humanas, Universidade de São Paulo. São Paulo, 2013.

MARQUES, Davina; CARELLI, Fabiana B. Healing Representations in Literature and Cinema. In BRAY, Peter; BORLESCU, Ana Maria (Org.). Beyond Present Patient Realities. Oxford, United Kingdom: Inter-Disciplinary Press, 2015. p. 35-48.

NABAIS, Catarina Pombo."Deleuze: um L de Literatura" ou "A Literatura: uma vida". In ANGEL, Golgona (Org.). Jornada sobre o conceito de Poética. Escrever: porquê, para quê, para quem? FCUL, 30 maio 2008. Disponível em: <http://cfcul.fc.ul.pt/biblioteca/online/pdf/catarinanabais/deleuzeuml.pdf>. Acesso em 12 de nov. 2015.

PAUL, Sheila A. Assessment of critical thinking: A Delphi study. Nurse Education Today, 34(11), p. 1357-1360, 2014.

PICCARDI, Tatiana. Transformando sofrimento em narrativa e narrativa em uma nova vida. Revista Internacional de Humanidades Médicas, v. 3, n. 1, p.01-11, 2014. Disponível em: <http://www2.unifesp.br/centros/cehfi/documentos/revista_hum_med_ vol3_num1_2014.pdf>. Acesso em 20 de nov. 2015.

PLAPLER, Hélio. Comunicação Médico/Paciente vs. Relação Médico/Paciente. A Narrativa como ponte na construção do (re)conhecimento. Trabalho de Conclusão de Curso (Disciplina) - Faculdade de Filosofia, Letras e Ciências Humanas, Universidade de São Paulo, São Paulo, 2015. 
POMPILIO, Carlos E. A Tragédia da Doença - Bases Fenomenológicas da Medicina Narrativa. Revista de Letras, n. 32, vol. 2, p.11-23, ago./dez. 2013.

PREVE, Ana Maria H. Uma educação em linhas de fuga. In AMORIM, Antonio Carlos: MARQUES, Davina; DIAS, Susana Oliveira (Org.). Conexões: Deleuze e Vida e Fabulação e... Petrópolis, RJ: De Petrus; Brasília, DF: CNPq; Campinas, SP: ALB, 2011. . Mapas, prisão e fugas: cartografias intensivas em educação. 2010. 267 p. Tese (Doutorado em Educação). Faculdade de Educação, Universidade Estadual de Campinas, Campinas. São Paulo, 2010.

ROSA, João Guimarães. Manuelzão e Miguilim. Rio de Janeiro: Nova Fronteira, 1984. Primeiras Estórias. Rio de Janeiro: Nova Fronteira, 1988.

SARAMAGO, José. O conto da ilha desconhecida. São Paulo: Companhia das Letras, 1998. SPAGNOL, Gabriela S.; VALLER, Lenise, AVELLAR Wagner M. Improvement initiative in stroke care. Arquivos de neuro-psiquiatria 2015, 73 (11). Doi:10.1590/0004$-282 \times 20150144$.

Submetido em: 15-01-2016 Aprovado para publicação: 24-06-2016 